\title{
PESQUISA-AÇÃO EM SALA DE AULA: \\ UM TRABALHO COM A RETEXTUALIZAÇÃO MULTIMODAL
}

Roberta Garcia*

RESUMO: Para ensinar o Português integrado às tecnologias, é importante compreender as expectativas e os objetivos de aprendizagem dos alunos, uma vez que a interação em uma sociedade contemporânea exige práticas letradas mais complexas. É preciso que a escola, uma das principais agências de letramento, considere as práticas sociais em que a leitura e a escrita são utilizadas pelos alunos, nos ambientes digitais. Nesse sentido, nossa pesquisa partiu da implementação e análise de uma pesquisa-ação, focando a retextualização de letras de músicas para hipercontos, com ênfase na inserção de elementos multimodais. Nosso público-alvo foram alunos do $8^{\circ}$ e $9^{\circ}$ ano do Ensino Fundamental, em uma escola municipal em Brumadinho/MG. Com este trabalho, objetivamos verificar como se deu o processo de retextualização multimodal, além de analisar, por meio das teorias de Jewitt (2013), como os recursos multimodais foram inseridos no gênero retextualizado, para complementar e ampliar o sentido do texto. Como resultado percebemos a contribuição para a reflexão em relação à retextualização de textos impressos para hipertextos e à percepção de que os elementos multimodais não são simples artefatos inseridos ao texto escrito, mas sim elementos que agregam redes amplas de significados.

PALAVRAS-CHAVE: Ensino; Hipercontos; Multimodalidade; Retextualização; Tecnologias

\section{Introdução}

O momento sócio-histórico que atravessamos, na contemporaneidade, possibilitanos a percepção de que, no contexto informal, há o protagonismo da tecnologia entre pessoas de todas as idades. Nesse panorama, o conhecimento e a troca de informação se dão de maneira cada vez mais intensa, por meio da Internet, das diversas mídias e das redes sociais, possibilitando novos eventos de letramentos que exigem conhecimentos cada vez mais complexos. Sendo assim, há indícios de que as práticas de letramentos convencionais comecem a se tornar insuficientes para que o sujeito esteja efetivamente inserido na sociedade. Pode-se argumentar, nesse sentido, que os letramentos digitais já estabelecem forte

\footnotetext{
${ }^{*}$ Doutoranda em Linguística Aplicada, na linha de Linguagens e Tecnologia, pela Universidade Federal de Minas Gerais (UFMG). Mestre em Linguística Aplicada, com ênfase em ensino de leitura e escrita em língua materna, pela UFMG. Pós-graduada em Atendimento Educacional especializado pela Universidade Federal do Ceará (UFC). Professora de Língua Portuguesa, com 20 anos de experiência, no ensino básico.
} 
influência na produção e na leitura dos diversos gêneros textuais e multimodais emergentes nas esferas digitais, possibilitando ao sujeito letrado uma participação nos mais importantes papéis sociais.

Em âmbito escolar, no entanto, nem sempre vemos refletir o mundo vivenciado pelos alunos, em seu cotidiano. Podemos dizer que o uso de tecnologias não acontece com tanta frequência e, muitas vezes, o alunado é até impedido de utilizá-las, em salas de aula. Como nos alerta Rojo (2012, p. 99), "um dos letramentos muitas vezes relegado a segundo plano nas esferas escolares é aquele que capacita o aluno a promover sentidos e a interagir com os gêneros digitais presentes nos ambientes tecnológicos aos quais os internautas têm acesso". Todavia, uma vez que as crianças e os adolescentes estão se autoletrando por meio dos aparatos tecnológicos, desafiando os sistemas educacionais tradicionais, é preciso ter em mente que a revolução inerente ao desenvolvimento tecnológico demanda uma transformação no processo de ensino e aprendizagem da língua materna.

Consideramos a retextualização uma estratégia eficaz para que o aprendiz seja capaz de perceber a migração do impresso para o digital, ressignificando a escrita e a leitura como eventos não-lineares e lançando mão da multimodalidade para ampliar o texto escrito, com elementos como cores, imagens, sons, sequências mais dinâmicas e, por vezes, até interativas. Nessa direção, o presente artigo discute o papel da produção textual em ambiente tecnológico e a importância da multimodalidade na ampliação dos textos em uma sociedade cada vez mais imersa em práticas de letramentos digitais. O trabalho aqui proposto se justifica pela emergência do reconhecimento da multiplicidade linguística que os alunos trazem de suas vivências para o ambiente escolar e da importância do fomento de habilidades desenvolvidas no trabalho com gêneros genuinamente digitais. Para tanto, apresentamos, aqui, a implementação de uma pesquisa-ação (THIOLLENT, 2011), proposta por meio de um projeto de ensino, cujos principais objetivos foram verificar como se dá o processo de retextualização de letras de músicas impressas para hipercontos, além de analisar como os recursos multimodais foram empregados ao gênero retextualizado, de acordo com os estudos de Jewitt (2013). Nosso público-alvo foram alunos de turmas do $8^{\circ}$ e do $9^{\circ}$ ano do Ensino Fundamental, de uma escola municipal em Brumadinho/MG. 
Como resultado, asseveramos que a pesquisa-ação implementada propiciou a promoção de uma aprendizagem de fato significativa, na medida em que favoreceu a produção de um gênero literário digital e a reflexão sobre a importância da inserção de elementos multimodais, não como simples aparatos que complementam o texto escrito, mas como redes de significados que ampliam o seu sentido. Assim, a proposta pedagógica aqui apresentada possibilitou a ampliação dos letramentos digitais e a correlação do aprendizado formal, dentro da escola, com o aprendizado informal, adquirido no mundo social, fora das instituições escolares.

Além da presente introdução, este artigo está dividido em seis seções. Na primeira, destacamos alguns aspectos próprios de produção textual e leitura em ambiente tecnológico, as quais favorecem a ampliação dos letramentos digitais. Subsequentemente, abordamos o conceito de retextualização, central para as atividades propostas no projeto de ensino descrito aqui. Em seguida apresentamos características do gênero hiperconto, conforme seu idealizador, Marcelo Spalding. Nas seções cinco e seis nos ocupamos em descrever os resultados da pesquisa-ação implementada, assim como as análises das inserções multimodais e da retextualização. Por fim, apresentamos nossas considerações finais, retomando assuntos basilares na produção deste artigo.

\section{A produção escrita e a prática de leitura mediadas pelas tecnologias: ampliação} dos letramentos digitais

O uso das tecnologias possibilita uma nova forma de interação, traz novos modos de comportamentos e transforma as relações sociais, por meio da leitura e da escrita em ambientes digitais. Os alunos, público-alvo desta pesquisa, por exemplo, relatam que, fora da escola, em contexto informal, utilizam a leitura e a escrita, principalmente, em mensagens de Whats $A p p$ e em redes sociais. Já no âmbito escolar, como dito acima, as práticas de letramentos, em grande medida, não envolvem o uso de tecnologias. Portanto, cientes de que o ambiente escolar deve refletir o que acontece nas práticas sociais, podemos argumentar que é de extrema importância que se alie à mobilização do ensino o uso de ferramentas 
digitais, a fim de possibilitar uma reflexão crítica sobre os conceitos de escritores e leitores multimidiáticos.

Para Marcuschi e Xavier (2004, p. 18), "um fato inconteste é que a Internet e todos os gêneros a ela ligados são eventos textuais fundamentais baseados na escrita. Na Internet, a escrita continua essencial apesar da integração de imagens e de som" (MARCUSCHI; XAVIER, 2004, p. 18-19). A ampliação das habilidades, no meio digital, se deve à constante necessidade de manuseio das tecnologias e à criação de formas específicas de lidar com a linguagem, já que, por meios digitais, o surgimento de gêneros emergentes é cada vez mais crescente. A noção de linearidade, como era nos processos de escrita e leitura em materiais impressos, foi modificada e os recursos agregados ao ato de ler e escrever também foram ampliados. Pode-se dizer, portanto, que o êxito das novas tecnologias está centrado nas diversas funções trazidas pela centralidade da escrita e pelo fato de propiciar a incorporação de multimodalidades, interferindo na natureza dos recursos linguísticos utilizados (MARCUSCHI; XAVIER, 2004, p. 13). Esse fato é determinante no fascínio que as tecnologias exercem nas práticas sociais de pessoas de todas as idades. Uma vez que o impacto das mídias tecnológicas favorece a construção de uma sociedade mais "textualizada" (YATES, 2000, p. 233 apud MARCUSCHI; XAVIER, 2004, p. 15), é crucial que a escola integre o uso das tecnologias ao ensino de produção textual, por meio dos gêneros discursivos. Logo, é certo dizer que a escrita e a leitura, com características multimidiáticas, podem ser conduzidas em um ensino estrategicamente sistematizado, possibilitando aos alunos a produção de textos de modo interativo e dinâmico.

Por fim, é importante ressaltar que o acesso às tecnologias, em ambientes formais de educação, favorece a interação social e a aquisição de informações essenciais para a formação de uma cidadania mais crítica. Em suma, com o uso de ferramentas tecnológicas, a escola passa a cumprir o importante papel de incluir digitalmente nossos alunos, tornando-os produtores de textos mais conscientes do processo de autoria e leitores mais participativos. 


\section{O ensino por meio de retextualização multimodal}

Um conceito fundamental para a pesquisa-ação apresentada neste artigo é o de retextualização. No Brasil, um dos primeiros postulados acerca desse tema surgiram nos estudos de Neuza Gonçalves Travaglia, em sua tese de doutorado, defendida em 1993, junto ao Departamento de Letras Modernas da Faculdade de Filosofia, Letras e Ciências Humanas da Universidade de São Paulo, a respeito da tradução. Marcuschi (2010, p. 46), tratando da retextualização da fala para a escrita, afirma que a retextualização não é "um processo mecânico, mas demanda conhecimento de gênero, suporte, tornando-se uma operação complexa que interfere tanto no código quanto no sentido".

Para Matêncio (2003, p. 3-4), “a produção de um novo texto a partir de um ou mais textos-base, revela que o sujeito trabalha sobre as estratégias linguísticas, textuais e discursivas identificadas no texto-base, projetando-as em uma nova situação de interação”. Já Dell'Isola (2013, p. 140) considera que as atividades de retextualização englobam várias operações que favorecem o trabalho com a produção de texto. Dentre elas, ressalta-se um aspecto de imensa importância que é a compreensão do que foi dito ou escrito para que se produza outro texto. Para retextualizar, ou seja, para transformar um gênero em outro, é preciso, inevitavelmente, que seja entendido o que se disse ou se quis dizer, o que se escreveu e os efeitos de sentido gerados pelo texto escrito (DELL'ISOLA, 2007, p. 14).

O conceito de retextualização, assumido aqui, associa-se à necessidade de se desenvolverem novas perspectivas educacionais relativas à linguagem e ao seu uso. A importância de um trabalho com essa técnica está no fato de auxiliar os alunos a analisarem criticamente os discursos materializados nos textos e a desenvolverem estratégias para o conhecimento e para a produção dos gêneros estudados. Ademais, os produtores textuais devem atentar à compreensão, não só em relação à estrutura textual, mas principalmente em sua função social é o que determina a escolha de elementos, como suporte, público-alvo, propósito comunicativo, linguagem mais adequada, entre outros aspectos, no ato da transformação de um gênero em outro. 
Neste trabalho, tratarei apenas das operações de retextualização que envolvem a as possibilidades de inserção multimodal. Desse modo, argumentamos que, se podemos considerar que a imagem também é um texto - não-verbal -, é possível levantar a hipótese de que a retextualização, além de ser a transformação de um gênero textual em outro (DELL'ISOLA, 2007), ou a passagem da modalidade oral à escrita (MARCUSCHI, 2010), pode ser também a transformação da modalidade escrita à multimodalidade, na medida em que se toma um texto verbal como texto-fonte para referenciá-lo por meio de imagens ou sons, conservando-se seu conteúdo original. Para a realização de tal atividade, é necessário que se pense em novos recursos, novas linguagens, novos propósitos comunicativos, entre outros elementos necessários para a transformação de um texto em outro. Em síntese, passamos a cunhar de retextualização multimodal o processo retextualizador envolvendo a conversão de qualquer gênero, seja ele escrito, oral, ou até mesmo visual, em outro.

\section{O hiperconto}

É importante salientar que o hiperconto, gênero proposto para a retextualização na pesquisa-ação aqui apresentada, caracteriza-se como um gênero literário genuinamente de ambiente digital. A idealização do hiperconto surgiu em meados de 2008, quando Marcelo Spalding, em seu mestrado, investigou de que forma a literatura estava presente na Internet e como seria sua permanência nas mídias. No entanto, foi em 2009 que o autor resolveu estudar sobre romances colaborativos e ciberpoemas e começou o trabalho com o hiperconto, termo que jamais havia sido utilizado em estudos literários.

Segundo Marcelo Spalding (2009), o hiperconto é uma versão do conto para a Era digital. De natureza ficcional, trata-se de uma narrativa em formato de hipertexto. De acordo com o autor, esse gênero requer narratividade, intensidade, tensão, ocultamento e autoria. Spalding diz, ainda, que o texto escrito é o cerne do hiperconto, preservando o seu caráter literário, mas conta com imagens (em movimento ou estáticas), áudios, biperlinks, interatividade e quebra de linearidade.

A interatividade presente nos hipercontos permite que o leitor navegue pelo texto, fazendo escolhas entre rumos predeterminados pelo(s) autor(es), o que reforça a ideia de 
Miller (2015), quando fala que a Internet transforma o público em comunidades participativas, na medida em que o próprio leitor vai percorrendo seu caminho, participando da construção do sentido do texto. Assim, a cada conflito presente na narrativa, o leitor se vê diante de links que possibilitam diferentes caminhos para a continuidade do enredo. Os recursos multissemióticos, como fotografias, imagens, vídeos, sons, músicas, gráficos, integram-se à materialidade linguística, ressignificando a experiência do leitor com os textos escritos, ampliando os efeitos de sentido e os significados do texto.

$\mathrm{Na}$ escrita de um hiperconto, é preciso que o autor - de acordo com as especificidades do gênero - compreenda a importância dos conflitos na narrativa; entenda a relevância dos linkes no texto e saiba inseri-los; compreenda o uso de diversas linguagens; seja capaz de inserir imagens, sons, vídeos, cores que possam dialogar com o texto escrito. Para produzir um hiperconto, o autor pode escrever sozinho ou, como é comum em outros gêneros digitais, recorrer à escrita colaborativa. No mais, ao convidar os leitores a criarem seus próprios hipercontos, o idealizador, Marcelo Spalding, deixa um espaço propício para a participação e colaboração do público.

\section{A pesquisa-ação: o processo de retextualização multimodal de letras de músicas ao hiperconto}

Nossa pesquisa-ação tomou como base os estudos de Thiollent (2011), para quem a pesquisa-ação é

um tipo de pesquisa social com base empírica que é concebida e realizada em estreita associação com uma ação ou com a resolução de um problema coletivo e no qual os pesquisadores e os participantes representativos da situação ou do problema estão envolvidos de modo cooperativo ou participativo. (THIOLLENT, 2011, p. 20)

Ainda, segundo Thiollent (2011), a pesquisa-ação é considerada como um método que concebe e organiza uma pesquisa social de finalidade prática que esteja de acordo com as exigências próprias da ação e da participação dos atores da situação observada. 
Nesse sentido, a pesquisa-ação encontrou um contexto favorável para a implementação do nosso projeto de ensino, na medida em que tem como ponto de partida a observação de um problema em sala de aula, qual seja: o trabalho com a leitura e escrita na escola, em certa medida, ainda acontece de maneira tradicional, em que se prioriza o texto verbal e impresso como a principal tecnologia. Tal hipótese é corroborada pela afirmação de Ribeiro (2016, p. 42), no sentido de que, “de forma geral, os textos imagéticos são pouco trabalhados nas escolas, sendo comum que apareçam apenas como 'ilustração' do texto escrito ou ilustração 'em diálogo' com esse texto” (grifos do autor). Essa abordagem tornase, em certa medida, superficial e não desperta o interesse dos alunos, transformando-se em um estorvo para uma aprendizagem mais participativa.

Por meio de observação em sala de aula, pudemos constatar que os alunos, tendem a priorizar, em suas leituras e produções, o texto escrito, desconsiderando os recursos multimodais como uma "rede ampla de significados" (MENEZES, 2008, p. 324), e como "uma dimensão semântica de profunda importância” (KRESS E VAN LEEUWEN, 2006, p. 45). Seguindo, foram gerados registros, por meio de diário de bordo, observação participativa, fotografias e gravação em vídeo, que serviram de embasamento para a elaboração das etapas metodológicas de um projeto de ensino que visa à prática de uma intervenção consciente e sistematizada. Além disso, todos os participantes desempenham papéis ativos, de forma colaborativa, com a intenção de transformar o problema encontrado.

Nossa pesquisa-ação foi implementada em uma escola municipal, em Brumadinho/MG, com alunos de $8^{\circ}$ e $9^{\circ}$ anos. A escolha do público-alvo se deu por observarmos o interesse dos alunos em trabalhos que envolvem a tecnologia e, como já dito, pelo fato de os alunos não atentarem para a importância da linguagem multimodal que os cerca todos os dias. A situação sociocomunicativa realizada pelos alunos foi a seguinte: participação em um projeto de ensino com a proposta de que fizessem uma retextualização para a transformação dos textos-fonte, letra de música, em contos, para, depois, se desenvolverem em 
hipercontos. A publicação dos textos finais foi feita em um sitet criado pelos próprios alunos, com a intervenção da professora-pesquisadora. Para a divulgação do site, foram confeccionados cartazes e panfletos em que os alunos convidaram toda a comunidade escolar para o acesso e leitura participativa, instigando-os a deixarem seus comentários.

\section{Desenvolvimento do projeto de ensino}

O projeto de ensino foi implementado por meio de nove oficinas, com duração de 20/horas-aula, com atividades sistematizadas, partindo da leitura/escuta e análises de aspectos estruturais e sociocomunicativos de letras de músicas e de um exemplar de hiperconto, para, depois, partirem para a produção de um conto e seu desdobramento em um hiperconto. Abaixo, descrevo as oficinas implementadas:

A primeira oficina se iniciou com a leitura/audição da música "Caminho das Rosas", de Mc Martinho. O objetivo era que os alunos fizessem a análise e comparação da letra da música e da retextualização que resultou em um conto policial, com o mesmo título, de autoria de Felipe Ramon. Este conto foi produzido por um aluno da mesma escola, em uma pesquisa-ação desenvolvida na minha dissertação de mestrado, defendida em 2015, que contava com atividades de retextualização.

Os alunos puderam observar a manutenção das informações narradas na música e a extrapolação, com alguns detalhes que não ficavam claros ao leitor na letra musical. Perceberam, também, que na transformação de um gênero a outro, era necessária a modificação estrutural; a transposição, em algumas partes do texto retextualizado, do registro informal para o formal; o acréscimo de modalizadores temporais e indicação de lugares e acontecimentos. Verificaram, em uma análise global, que houve subtrações e substituições de vocábulos e de fatos. Por fim, os alunos fizeram uma comparação referente aos elementos narrativos dos dois gêneros.

${ }^{1}$ Disponível em:<garciaroberta38.wixsite.com/contosehipercontos>. Acesso em: 10 jan. 2020. 
Na segunda oficina, os alunos foram convidados a ler/escutar a música "Domingo no Parque", de Gilberto Gil. O objetivo desta oficina era que os alunos comparassem aspectos sociocomunicativos entre a letra da música citada e um conto retextualizado, com o mesmo título, dos alunos Aliff Santos e Darlan Ferreira. Este conto também é fruto do projeto de ensino implementado em meu mestrado. Assim, eles puderam perceber semelhanças e diferenças em relação ao público-alvo, suporte, propósito comunicativo, registro de linguagem, entre outros. Além disso, os alunos fizeram análises, comparando a construção da situação inicial, do tempo, do espaço, do conflito, do clímax e do desfecho, entre o texto-fonte e o texto retextualizado.

$\mathrm{Na}$ terceira oficina, foram analisados trechos de músicas de Chico Buarque, como "O meu guri", "Minha história", "Pivete", "Vida", "Roda-viva"; "João e Maria" e "Todo o sentimento". O objetivo era que os alunos, com base nos trechos, fizessem uma primeira retextualização, transformando-os em um conto. Os alunos fizeram as produções, mantendo trechos e agregando elementos modalizadores específicos de textos narrativos. Atentaram, também, para a sequência de fatos e para a temporalidade. Acrescentaram informações e subtraíram outras. Adequaram o registro linguístico para transformar os trechos das músicas em contos. Após isso, leram e compararam as suas produções. Com isso, os estudantes deram os primeiros sinais de terem entendido o processo de retextualização.

$\mathrm{Na}$ quarta oficina, os alunos se agruparam e escolheram as letras das músicas para serem retextualizadas. Em seguida, cada grupo analisou o tema, os personagens, o cenário, a temporalidade e o enredo das letras das músicas escolhidas. Além disso, em um quadro, os estudantes planejaram a retextualização, selecionando as informações principais que comporiam o texto, como seria a sequência dos fatos e se ativeram à linguagem mais adequada, de acordo com o público-alvo, com o suporte e com o propósito comunicativo. Assim, produziram contos que seriam desdobrados, posteriormente, para se transformarem em hipercontos.

Na quinta oficina, o quadro de planejamento de retextualização de um grupo foi entregue a outro grupo, a fim de que analisassem se o conto contemplou o que foi proposto inicialmente. Outro objetivo era que os colegas dessem sugestões de melhoria no texto dos 
outros colegas. Após isso, a professora-pesquisadora analisou e deu o feedback sobre as produções dos alunos, utilizando bilhetes orientadores e uma grade correção, com a intenção de trazer, também, sugestões de adequações.

Na sexta oficina, os alunos foram levados ao laboratório de informática, para terem o primeiro contato com o gênero hiperconto. $\mathrm{O}$ texto escolhido pela professora-pesquisadora foi "Um estudo em vermelho", de Marcelo Spalding. Os alunos puderam navegar no site e se encantaram, ao perceberem que, conforme os links escolhidos, a história tomava diferentes rumos. Os estudantes comentaram entre si sobre as escolhas e sobre os diferentes finais apresentados no hiperconto. Por meio das atividades propostas, os alunos analisaram elementos multimodais, como cores, letras, sons, imagens e links que remetiam a termos específicos, como, por exemplo, um link sob o nome do autor Edgar Allan Poe que, ao ser acionado, remetia a informações biográficas em páginas da Wikipédia. Tais recursos enfatizam a não-linearidade do gênero digital hiperconto, além de correlacionar o enredo a fatos e personalidades. Após isso, os alunos deixaram comentários, no site de Spalding, e relataram as semelhanças e diferenças observadas entre letras de músicas, contos e hiperconto. Os estudantes escreveram, ainda, a sua própria definição do gênero hiperconto, que seria publicada no site que construiríamos a seguir.

Na sétima oficina aconteceu a retextualização dos contos, produzidos com base nas músicas escolhidas, para hipercontos. Os grupos se dividiram e designaram a responsabilidade de cada parte do texto aos integrantes. Assim, a partir da situação inicial, que seria mantida em todos os hipercontos, os alunos escreveram outras versões de cada parte: conflito, tentativa de resolução, clímax e desfecho. Após a produção das partes e conferência da professora-pesquisadora, foi o momento de escolherem os elementos multimodais que seriam inseridos: imagens, sons, músicas, letras, cores, entre outros.

A oitava oficina foi dedicada à revisão e reescrita dos hipercontos. Os alunos e a professora-pesquisadora verificaram se havia coerência e coesão entre as partes do texto, fizeram as revisões ortográficas e analisaram se a textualidade estava adequada. Observaram se os elementos multimodais dialogavam com o enredo e em que medida ampliavam o 
sentido do texto. Os alunos preencheram um quadro, a fim de verificarem se as suas produções estavam de acordo com o que haviam planejado e se possibilitaria uma leitura interativa e atraente. Isso feito, os aprendizes, com a orientação da professora-pesquisadora, construíram coletivamente um site, no qual inseriram o texto escrito e os recursos multimodais. Assim, aprenderam a trabalhar com a ferramenta Google Docs e a gerar links que teriam de acoplar em cada página, para que o leitor escolhesse o percurso que seguiria até chegar ao desfecho pretendido. Ao final das oficinas, os alunos divulgaram o trabalho, por meio de cartazes e panfletos, e convidaram os leitores a deixarem seus comentários.

Os participantes relataram que o trabalho com a tecnologia e com o gênero hiperconto foi uma inovação e sugeriram que fossem feitos mais trabalhos como aquele, nas escolas. O interesse pelo trabalho foi demonstrado pela participação massiva dos alunos.

\section{Análise da inserção multimodal e da retextualização}

Apresentamos, a seguir, as análises, primeiramente das inserções multimodais feitas pelos alunos, conforme os pressupostos teóricos de Jewit (2013). Em seguida, analisamos o processo de retextualização multimodal.

\section{Análise do hiperconto, de acordo com Jewitt (2013)}

Jewitt (2013) conceitua a multimodalidade como "uma abordagem interdisciplinar extraída da semiótica social que entende comunicação e representação como mais que a linguagem e atende sistematicamente a interpretação social de uma variedade de formas fazendo sentido". De acordo com a autora, a multimodalidade investiga a interação entre significados comunicacionais e desafia a predominância prévia da linguagem falada e escrita, que passam a ser vistas como partes de um conjunto de sistemas multimodais. Sobre os conceitos-chave, Jewitt fala de alguns fundamentais para a multimodalidade: a) modo; b) recurso semiótico, c) materialidade, d) affordance modal, e) conjuntos multimodais e f) funções de significado. Assim, passamos a analisar, de acordo com conceitos da autora, o 
gênero digital hiperconto, tendo como corpus o site denominado "Contos e Hipercontos: literatura digital interativa", criado pelos alunos, participantes dessa pesquisa, e pela professora-pesquisadora, em 2015.

Segundo a Jewitt (2013), modo é o conjunto de recursos social e culturalmente moldados para fazer sentido: um "Canal” de representação ou comunicação (KRESS E VAN LEEUWEN, 2006 - grifos nossos). O site que hospeda os hipercontos conta com uma estrutura reconhecida social e culturalmente, na medida em que nele são inseridos menus e links, recursos esses habituais em hipertextos encontrados em ambientes digitais, como se pode ver na imagem abaixo.

Figura 1 - Site de hipercontos

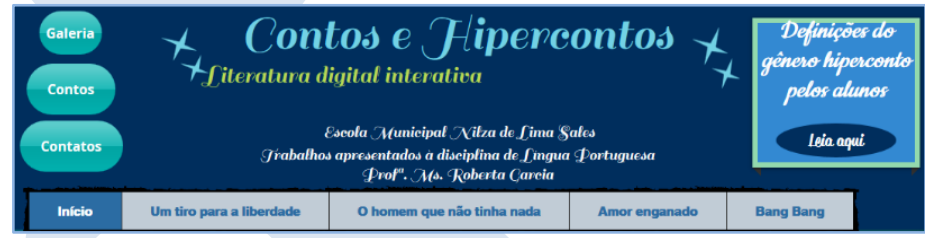

Fonte: http://garciaroberta38.wixsite.com/contosehipercontos

Além disso, como se espera, em textos literários digitais, há a presença de multissemioses, envolvendo a combinação de sentidos entre a escrita e outros recursos multimodais: fontes de cores e formatos variados, imagens, fundos coloridos (estáticos ou em movimento) e sons. Quanto aos recursos semióticos, Jewitt (2013) diz referir-se a um meio de significado simultâneo, envolvendo material, recurso social e cultural. Os recursos semióticos utilizados para a produção e circulação dos hipercontos, segundo os exemplos da autora, são: computador, notebook, tablet, smartphone, hardware, software e sites, naturalmente, já que se trata de um texto digital.

Já a materialidade, segundo Jewitt (2013), refere-se a como os modos são levados para ser o produto do trabalho dos agentes sociais moldados em material físico em recursos semióticos culturais. Em outras palavras, é o modo de organização dos recursos multimodais na página. Ao analisar as páginas iniciais do hipercontos constantes do corpus deste trabalho, pode-se verificar que no topo da página, em destaque, a palavra "hipercontos", já 
direciona o leitor para o gênero. Os menus também são destacados, aparecendo em cima, em cores diferenciadas, em todas as páginas, dando ao leitor a oportunidade de navegar, a qualquer momento da leitura, para outras páginas do site.

Ainda na página inicial do site analisado, as imagens se movimentam e servem para chamar a atenção do leitor e para relacionar os títulos e os enredos dos hipercontos. Além disso, há outros ícones com links, inseridos no topo, para o leitor navegar (definição do gênero, contos, galeria e contatos). O leitor pode escolher entrar nos hipercontos pelo menu, pelas imagens móveis, pelos títulos, abaixo das imagens em destaque, pelos ícones "leia mais", ou pelas situações iniciais, narradas abaixo das imagens, instigando a curiosidade do leitor, como se pode observar na figura 2.

Figura 2 - Site de hipercontos

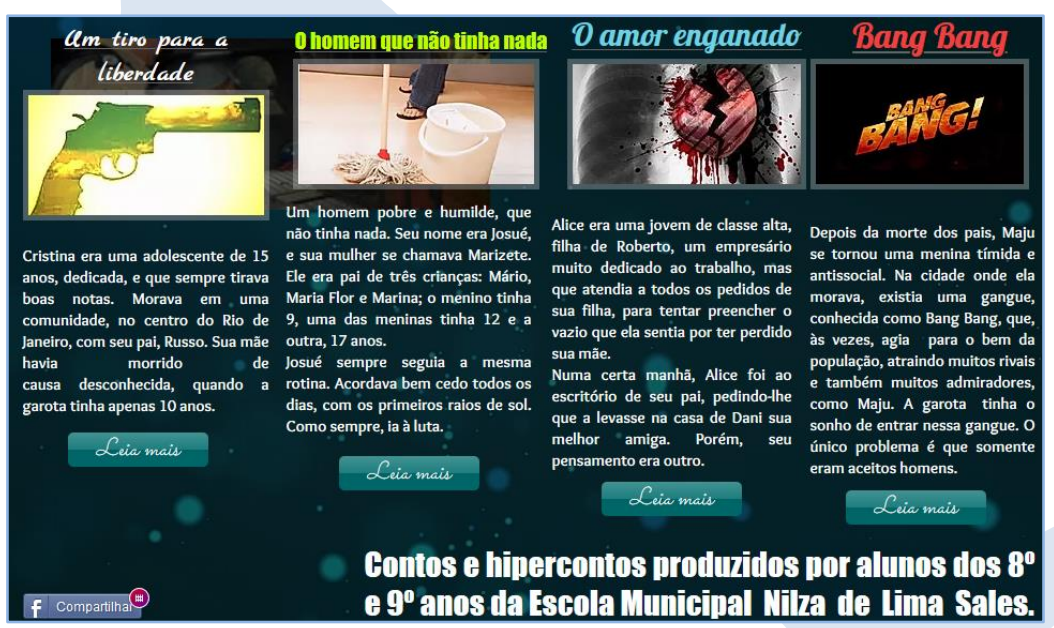

Fonte: http://garciaroberta38.wixsite.com/contosehipercontos

Segundo Jewitt (2013), os Affordances modais referem-se às possibilidades e restrições de diferentes modos - o que é possível expressar e representar ou comunicar facilmente com os recursos de um modo e o que é menos direto ou mesmo impossível. Nos hipercontos, podem ser encontrados diversos affordances modais. Para iniciar, exemplificamos a possibilidade de interação e participação do leitor nas histórias, que se dá pela escolha dos caminhos de leitura, para se chegar ao final de sua preferência, por meio de subtítulos com 
links, em destaque com cores diferentes. Tais recursos podem funcionar como atitudes responsivas do leitor.

Figura 3 - Site de hipercontos

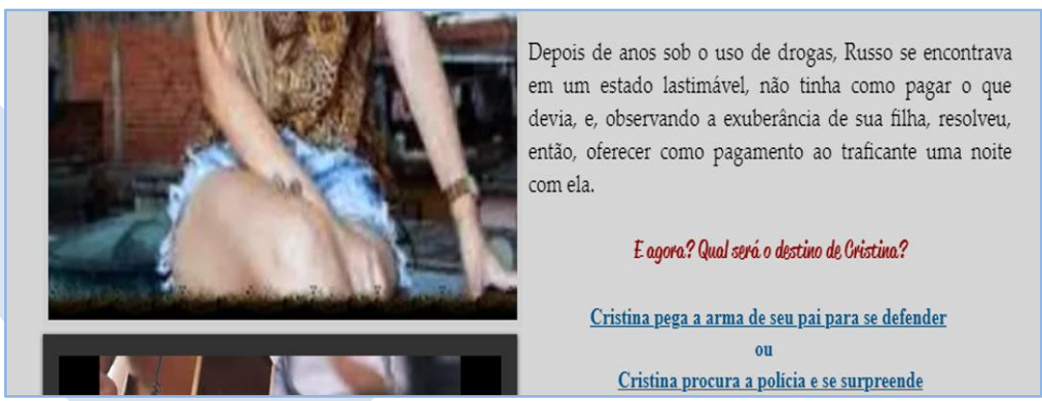

Fonte: http://garciaroberta38.wixsite.com/contosehipercontos

Outro tipo de affordance modal encontrado são as possibilidades de comentários e depoimentos dos leitores, ao final da leitura. Além da possibilidade de contatos com os idealizadores dos sites, conforme demonstram as figuras 4 e 5 .

Figura 4 - Site de hipercontos

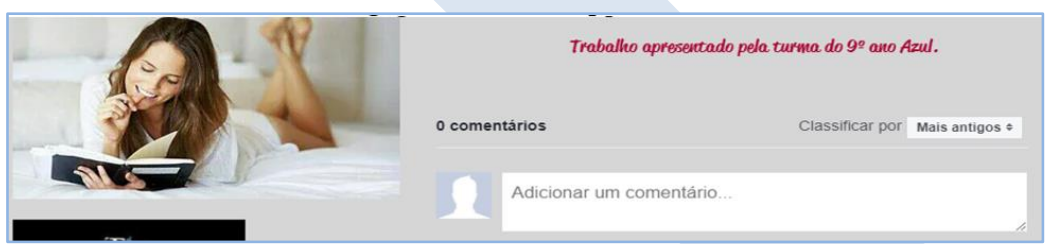

Fonte: http://garciaroberta38.wixsite.com/contosehipercontos

Figura 5 - Site de hipercontos

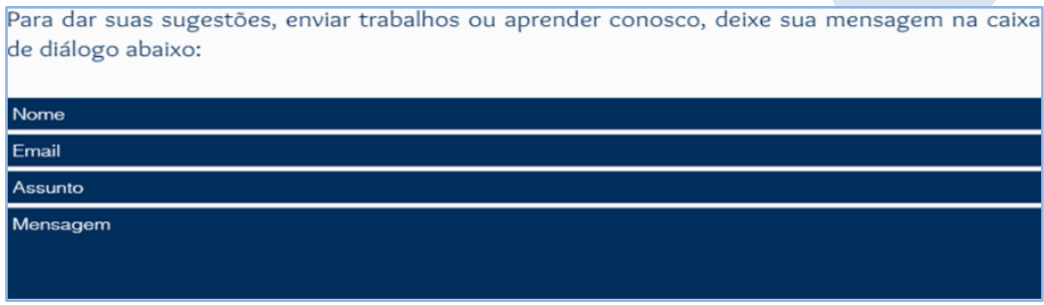

Fonte: http://garciaroberta38.wixsite.com/contosehipercontos 
O affordance de contato com os idealizadores do site funciona como uma ferramenta utilitária, principalmente para outros professores que pretendem implementar um projeto com hipercontos, em sala de aula, pois, assim, poderão pedir sugestões teóricas, tirar dúvidas e ter os projetos dos autores como subsídios.

Quanto aos conjuntos multimodais, conforme Jewitt (2013), são representações ou interações que consistem em mais de um modo. Além de todos os conjuntos já citados, os hipercontos também contam com imagens que se relacionam com os enredos constantes em cada página escolhida pelo leitor. $\mathrm{Na}$ figura abaixo, a imagem do carro de polícia em movimento retrata o enredo que fala sobre a protagonista acompanhar os policiais até o local de denúncia.

Figura 7 - Site de hipercontos

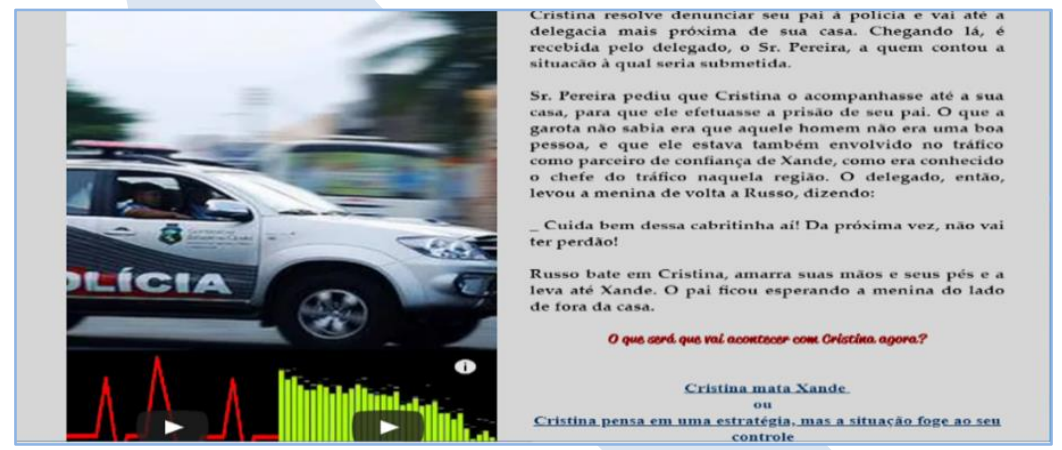

Fonte: http://garciaroberta38.wixsite.com/contosehipercontos

Nessa página, como em várias do site "Contos e hipercontos: literatura digital interativa", pode-se ver, abaixo da imagem, ícones com sons. No caso desse trecho, há o som de uma sirene, o que propicia uma relação de sentido com o texto escrito e com a imagem, possibilitando uma leitura multissemiótica.

$\mathrm{Na}$ próxima figura, além do conjunto multimodal, formado por letras de diferentes cores, corpo do texto, subtítulos, imagem (uma mulher segurando uma arma) e sons (de tiros), possibilitando a relação de sentidos, há, ainda, um vídeo que contém uma música, 
causando o efeito de suspense (The Phanton of the Opera). Os sons sempre são acionados, assim que o leitor abre a página.

Figura 8 - Site de hipercontos

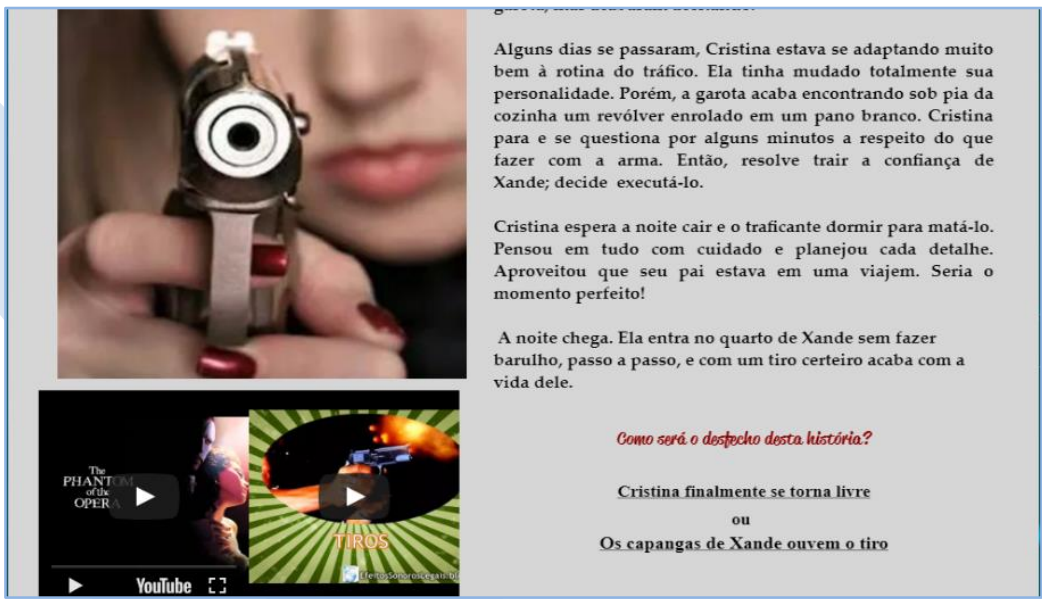

Fonte: http://garciaroberta38.wixsite.com/contosehipercontos

A função de significado, de acordo com Jewitt (2013) é a construção da multimodalidade sobre uma teoria funcional do significado, uma ideia de significado como ação social realizada através de escolhas modais situadas das pessoas e do caminho. Como se pode ver, os conceitos-chave, propostos pela autora, são imbricados, o que proporciona uma análise correlacionada. A construção de sentidos é feita social e culturalmente, na medida em que as imagens escolhidas pelos autores estão relacionadas ao conhecimento de mundo do leitor. No caso da figura 8, por exemplo, pode-se ver a relação das imagens com as palavras “arma”, "executar" e a própria ideia de armamento com a situação de "tráfico de drogas". A música que causa suspense também é relacionada com o enredo de todo o hiperconto, na medida em que o suspense é parte integrante da história. 


\section{Análise da retextualização multimodal}

Nas análises subsequentes, daremos ênfase à retextualização multimodal, que implica fazer uso de diversos modos para representar e ampliar o sentido do texto retextualizado. Para a análise da retextualização, escolhemos o hiperconto "O homem que não tinha nada", retextualizado da música com o mesmo título, de autoria de Projota. Inicialmente, é importante dizer que a música em questão é muito conhecida entre os jovens e adolescentes; por isso, foi escolhida por um grupo de alunos do $8^{\circ}$ ano. A letra da música é de fácil entendimento. Conta a história de uma família de renda baixa, narrando o dia a dia do protagonista, que é um faxineiro. No desfecho, o senhor é morto por um bandido.

Pode-se observar, nas figuras abaixo, que as páginas do hiperconto são construídas com imagens relacionadas ao enredo. Os autores inseriram imagens de pessoas de origem humilde, para representar o protagonista e sua família (Figura 9). Além disso, inseriram a imagem de uma pessoa com um balde um esfregão, relacionando à palavra (esfregão) e ao emprego de faxineiro do personagem (Figura 10), constantes no texto-fonte.

Figura 9-Site de hipercontos

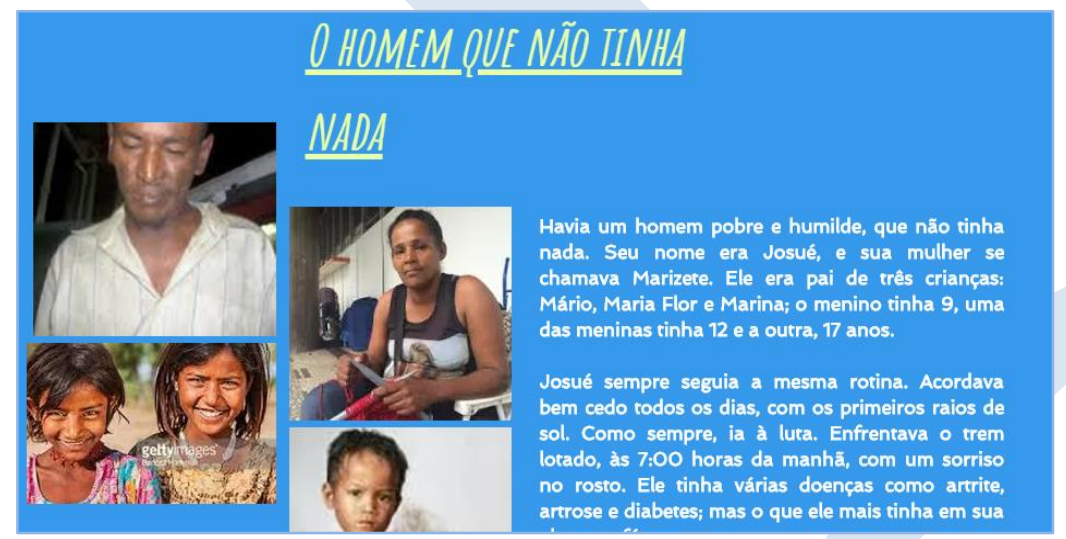

Fonte: http://garciaroberta38.wixsite.com/contosehipercontos 
Figura 10 - Site de hipercontos

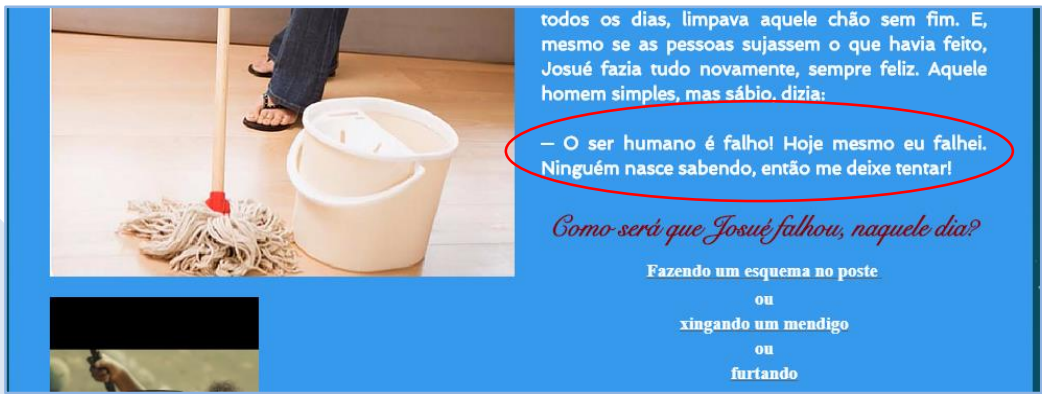

Fonte: http://garciaroberta38.wixsite.com/contosehipercontos

Quanto à produção escrita, os autores citaram trechos da música, como o horário em que o protagonista sai para trabalhar, o trem lotado, as doenças do protagonista, e, em destaque na figura 10, o refrão da música. Em relação à extrapolação, é um recurso necessário na retextualização do hiperconto, uma vez que os autores produziram outras partes que tiveram que acoplar ao texto original. Uma demonstração de extrapolação, na figura abaixo, é a criação dos nomes das personagens: protagonista (Josué), esposa (Marizete) e dos filhos (Mário, Maria Flor e Marina), que não eram relatados na letra da música.

A figura abaixo, demonstra a referência ao desfecho da música, momento em que o protagonista é atacado por um bandido.

Figura 11 - Site de hipercontos

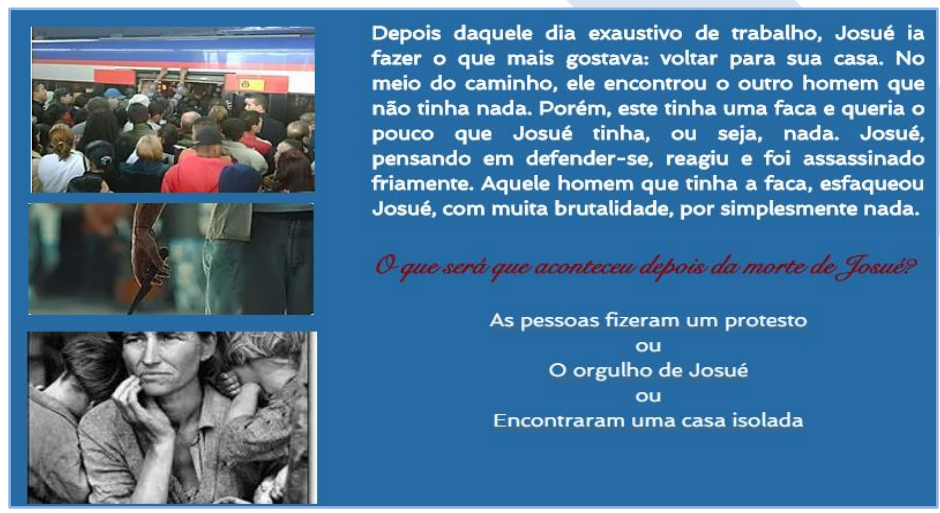

Fonte: http://garciaroberta38.wixsite.com/contosehipercontos 
Quanto à retextualização multimodal, pode-se perceber a relação com o texto escrito em três imagens. A primeira faz referência à estação de trem lotada, no momento que o protagonista estava voltando para a sua casa. A segunda mostra um homem com uma faca na mão, instrumento utilizado para atacar o protagonista. A terceira mostra uma mulher, para representar a esposa de Josué, em companhia dos filhos, com expressões de tristeza pela morte do homem. A extrapolação retextual é percebida com a continuação da história, após a morte do protagonista, nos links ofertados para o leitor escolher o desfecho do hiperconto.

Os autores consideraram, ainda, a importância de citar o texto-fonte, ao final do hiperconto (Figura 12), como uma atitude ética, para não ser considerado plágio. O clipe oficial e a indicação de autoria da música propiciam ao leitor o conhecimento do texto inspirador do hiperconto, fazendo uma relação entre o texto-fonte e o processo de retextualização.

Figura 12 - Site de hipercontos

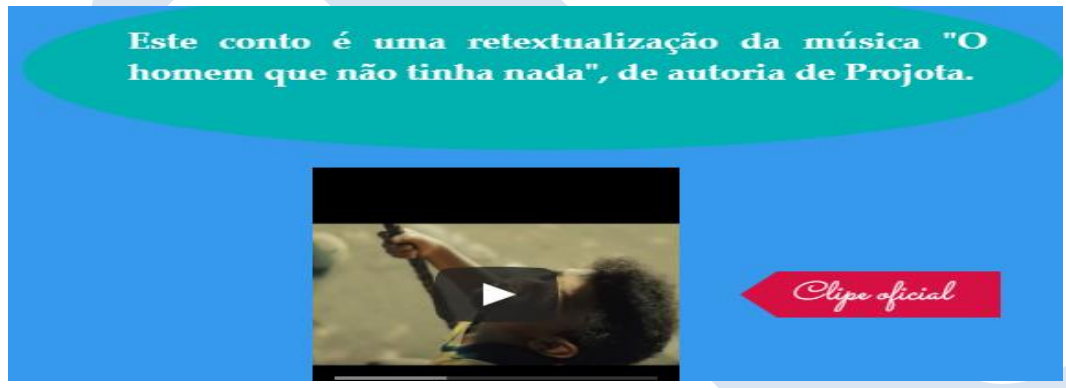

Fonte: http://garciaroberta38.wixsite.com/contosehipercontos

Enfim, o hiperconto é um gênero muito rico em relação a artefatos multimodais, o que proporciona análises mais detalhadas do que as apresentadas neste artigo. Contudo, procuramos exemplificar com amostras que consideramos mais interessantes e mais pertinentes à luz das teorias de Jewitt (2013) e de acordo com o nosso conceito de retextualização multimodal. 


\section{Considerações finais}

Com a evolução da definição textual, entram em cena conceitos como multimodalidade e hipertexto, que constituem novas formas de interação. Desse modo, se antes a única modalidade considerada texto era a escrita, agora a ideia de texto se expande em outros modos de representação. De acordo com o que afirmam Rodrigues et al. (2012, p. 138), a questão da multimodalidade, hoje cada vez mais presente nos textos, traz novas demandas para o professor de Língua Portuguesa. Sem esquecer a questão dos textos exclusivamente verbais, ou seja, da modalidade verbal dos textos, a multimodalidade precisa ser trabalhada em sala de aula tanto nas aulas de leitura/escuta quanto nas de produção textual. Destaca-se, ainda, a preocupação em se pensar a materialidade textual como não exclusivamente verbal e voltar o olhar para as diversas representações textuais existentes.

Desse modo, a integração do trabalho com os gêneros digitais e não-digitais leva em consideração tanto as semelhanças e como as diferenças existentes entre os diferentes gêneros, nos dois ambientes, propiciando o reconhecimento de que o aluno deve ser capaz de escolher que gênero utilizar em cada objetivo de leitura/escrita e nos diversos ambientes de comunicação.

Para a realização da pesquisa-ação, os alunos produziram hipercontos tendo como texto-fonte letras de músicas impressas, proposta essa que dialoga com a concepção de Rojo (2012), por pressupor uma imersão em práticas culturais de leitura e escrita (digital), relacionando-as com outras manifestações culturais (digitais e não-digitais), através de análises sistemáticas dos dois gêneros estudados, levando-se em consideração as multissemioses presentes nas linguagens.

Como forma de propiciar o interesse e a participação ativa dos alunos, nas aulas de Português, acreditamos que o trabalho com a retextualização multimodal favoreceu a promoção de atividades de leitura e escrita significativas, uma vez que consideram as condições de produção e de circulação de textos reais e que desenvolvem a reflexão sobre a importância da inserção multimodal, ampliando, assim, as práticas de letramentos digitais dos estudantes. 


\title{
CLASSROOM RESEARCH: \\ A WORK WITH MULTIMODAL RETEXTUALIZATION
}

\begin{abstract}
To teach technology-integrated Portuguese, it is important to understand students' expectations and learning objectives, as interaction in a contemporary society requires more complex literate practices. The school, one of the leading literacy agencies, needs to consider the social practices in which reading and writing are used by students in digital environments. In this sense, our research starts from the implementation and analysis of an action research, focusing on the retextualization of lyrics for hypercounts, with emphasis on the insertion of multimodal elements. Our target audience were 8th and 9th grade students in a municipal school in Brumadinho / MG. With this work, we aimed to verify how the process of multimodal retextualization took place, besides analyzing, through Jewitt's theories (2013), how multimodal resources were inserted in the retextualized genre, to complement and broaden the meaning of the text. As a result we realize the contribution to the reflection regarding the retextualization of printed texts to hypertexts and the perception that multimodal elements are not simply artifacts inserted into the written text, but elements that aggregate broad networks of meanings.
\end{abstract}

KEYWORDS: Teaching; Hypercounts; Multimodality; Retextualization; Technologies

\section{REFERÊNCIAS}

DELL'ISOLA, R. L. P. Retextualização de gêneros escritos. Rio de Janeiro: Lucerna, 2007.

GARCIA, R. Contos e hipercontos: literatura digital interativa (2015). Disponível em: < http://garciaroberta38.wixsite.com/contosehipercontos> Acesso em: 10 jan. 2020.

JEWITT, C. Multimodal methods for researching digital technologies. In: PRICE, S; JEWITT, C; BARRY B. (Orgs.) The SAGE handbook of digital technology research. SAGE: Los Angeles, p. 250-265, 2013. Disponível em:<https://www.researchgate.net/publication/293275174_Multimodal_methods_for_researching_digital_technologies $>$ Acesso em: 28 dez. 2019.

KRESS, G. van LEEUWEN, T. Reading Imagens: The Grammar of Visual. Nova York: Routledge, 2006.

MARCUSCHI, L. A. Da fala para a escrita: atividade de retextualização. São Paulo: Cortez, 2007.

MARCUSCHI, L. A.; XAVIER, A. C. (Orgs.) Hipertexto e gêneros digitais. Rio de Janeiro: Editora Lucerna, 2004.

MATÊENCIO, M. L. M. Referenciação e retextualização de textos acadêmicos: um estudo do resumo e da resenha. In: III Congresso Internacional da Abralin. Anais. 2003. Disponível em:< http://www.letramento.iel.unicamp. br/publicacoes/artigos/referenciacao_e_retextualizacao_MariaMatencio.pdf.> Acesso em: 22 abr. 2015. 
MENEZES, V. Multimedia Language Learning Histories. In: KALAJA, P.; MENEZES, V.; BARCELOS, A.M.F. (orgs.) Narratives of Learning and Teaching EFL (p. 199-213). Basingstoke: Palgrave Macmillan, 2008.

MILLER, C. Genre as Social Action (1984), Revisited 30 Years Later (2014). Letras \& Letras, IV SIELP, v. 31, n. 3 (jul./dez. 2015) - ISSN 1981-5239. Disponível em:< http://www.seer.ufu.br/index.php/letraseletras>. Acesso em 10 jan 2020.

RODRIGUES, R. H. et al. Linguística textual: $4^{\circ}$ período. Florianópolis: UFSC/LLV/CCE, 2012.

ROJO, R. Pedagogia dos multiletramentos: diversidade cultural e de linguagens na escola. In: ROJO, R.; MOURA, E. Multiletramentos na escola. São Paulo: Parábola Editorial, 2012.

SPALDING, M. Um estudo em vermelho (2009). Disponível em: < http:/ /www.hiperconto.com.br> Acesso em: 28 jun. 2019.

THIOLLENT, Michel. Metodologia da pesquisa-ação. São Paulo, Cortez, 2011.

Recebido em: 15/01/2020. Aprovado em: 20/05/2020. 